\title{
Raman spectroscopy study of glass corrosion
}

\author{
Branislav Hruška* ${ }^{1}$, Tadeáš Gavenda ${ }^{2}$, Filip Vašiček ${ }^{2}$, Roman Svoboda ${ }^{3}$ \\ ${ }^{1}$ FunGlass, A. Dubček University of Trenčín, Študentská 2, SK-911 50 Trenčín, \\ Slovakia \\ ${ }^{2}$ Department of Glass and Ceramics, University of Chemical Technology, \\ Technicka 5, CZ-166 28 Prague, Czech Republic \\ ${ }^{3}$ Department of Physical Chemistry, Faculty of Chemical Technology, University of \\ Pardubice, Studentská 95, CZ-532 10 Pardubice, Czech Republic
}

Email address of the corresponding author: branislav.hruska@tnuni.sk

Keywords: alkali silicate glass; Raman spectroscopy; corrosion; glass surface; glass structure.

\begin{abstract}
Binary sodium silicate and potassium silicate glasses with different alkali content were exposed to the corrosion environment of 35\% hydrochloric acid $(\mathrm{HCl})$. Glass samples were measured by Raman spectroscopy and the spectra were compared with Raman spectra of original pristine glasses in order to observe structural changes induced by corrosion within the surface layer. The usage of confocal Raman spectroscope enabled the measurement of Raman spectra from the depths of few micrometres to document the range of structural changes. The results suggest the depolymerisation of silicate structure due to the growth of the corrosion layer on the surface. The decrease of D2 peak points at the decomposition of three-membered rings. In addition, it is assumed that the $\mathrm{Si}-\mathrm{O}-\mathrm{Si}$ angle changes within the surface layer.
\end{abstract}

\section{INTRODUCTION}

Silicate glass is widely used technological material in the various industrial fields, including many special applications. The usage of silicate glass is well-known from the commercial products (windows, glass containers, decorations), but it is also used for specialized purposes (optics, glass fibers). Therefore, silicate glass is used in many environments and is being exposed to various types of effects. Corrosion is a phenomenon that is being studied extensively for a long time. However, the study of corrosion processes was primarily focused on the field of metals and their alloys where the corrosion is explained by the interaction between the metal surface and corresponding anions. The dominant mechanisms of such corrosion are redox reactions and the kinetics of the process is mainly dependent on the transport through the corroded film. On the contrary, the mechanism of corrosion of glass and ceramics materials is different. Glasses are reacting preferentially with cations that might penetrate quite deeply into the material via diffusion mechanisms. The high melting temperatures of glasses suggest that diffusion coefficients of most elements are very low at normal temperatures and those materials are considered as resistant to corrosion [1]. Hence, glass materials are widely used due to their chemical resistance. The interactions between glass and hot water were studied already in 1950s [2, 3], but the first papers studying the ion-exchange mechanisms of corrosion can be dated to 
around 1970 [4-7]. Those studies documented the fast and structure-dependent proton/cation exchange and related volume contraction. Since then, more papers summarizing the various mechanisms of glass corrosion were published $[1,8,9]$ and many studies concerning the different aspects of corrosion were carried out including the dissolution of nuclear glasses [10 - 12], the weathering of crystal glass [13], or natural corrosion of historical glass [14 - 16]. In addition, the glass corrosion was also a subject of Monte Carlo simulations study [17].

Despite the phenomenon of glass corrosion is very well documented in numerous studies, the structural changes in silicate structure induced by corrosion processes are not still completely revealed. One of the most suitable methods for the structural study of glass is Raman spectroscopy. Moreover, Micro-Raman spectroscopy is very sensitive to even fine local changes, because of its spatial resolution of approximately $1 \mu \mathrm{m}$, when using confocal mode [18]. Numerous Raman spectroscopic studies focused on the glass structure were carried out for various glass systems. Boizot et al. $[19,20]$ observed and explained the changes of glass structure after irradiation. The extensive work of Matson et al. [21] summarizes the structural evolution with increasing alkali content, and also were studied multicomponent oxide and non-oxide glass systems [22 - 24], and Osipov et al. [25 - 27] studied borate glass systems using Raman spectroscopy. The aim of this work is to study changes of the glass structure induced by corrosion using the Raman spectroscopy.

\section{EXPERIMENTAL}

Eight glass samples were prepared for this experiment. A set of binary alkali silicate glasses with different contents of $\mathrm{Na}_{2} \mathrm{O}$ and $\mathrm{K}_{2} \mathrm{O}$ was melted and cut into the cylindrical shape with a diameter of approximately $5 \mathrm{~mm}$. The composition of the glasses is summarized in Tab. 1. The binary systems $\mathrm{Na}_{2} \mathrm{O}-\mathrm{SiO}_{2}$ and $\mathrm{K}_{2} \mathrm{O}-\mathrm{SiO}_{2}$ were chosen for this experiment as representatives of model binary glasses because of their simplicity and for the sake of more straightforward interpretation of results. The prepared samples had to be kept in vacuum, because a high content of alkali ions caused the immediate surface corrosion by air humidity.

\begin{tabular}{cllllllll}
\hline & Na16 & Na20 & Na25 & Na33 & K16 & K20 & K25 & K33 \\
\hline $\mathrm{SiO}_{2}$ & 84 & 80 & 75 & 67 & 84 & 80 & 75 & 67 \\
$\mathrm{Na}_{2} \mathrm{O}$ & 16 & 20 & 25 & 33 & - & - & - & - \\
$\mathrm{K}_{2} \mathrm{O}$ & - & - & - & - & 16 & 20 & 25 & 33 \\
\hline
\end{tabular}

Tab.1: Chemical composition of glass samples in mol. \%. Glass samples are further denoted according to the content of the particular alkali oxide (bolded symbols in the top line).

Subsequently, all prepared alkali silicate glasses were measured by Raman spectroscopy. Spectra were collected in multiple locations in order to ensure the reliable result and to avoid possible accidental measurement errors. It was difficult to measure the high-quality spectrum at samples with higher alkali content, due to the corrosion layer on the samples surface created by the air humidity (it took only minutes for glasses with high alkali content to be covered by corrosion layer). Hence, 
the measurement was complicated due to the lower intensity of the spectra and it was necessary to break some samples and measure the glass spectrum on the fresh breakage.

Glass samples were exposed to the corrosion environment of $35 \%$ hydrochloric acid $(\mathrm{HCl})$ and the exposure time was recorded. A wide range of exposure times was chosen in order to cover both the initial stage of corrosion process and the growth of larger corrosion products. The exposure times are summarized in Tab. 2.

\begin{tabular}{ccccccccc}
\hline & Na16 & Na20 & Na25 & Na33 & K16 & K20 & K25 & K33 \\
\hline $\begin{array}{c}\text { Time } \\
(\min )\end{array}$ & 160 & 640 & 2560 & 10240 & 320 & 1280 & 5120 & 20480 \\
\hline
\end{tabular}

Tab.2: Times of the exposure to $\mathrm{HCl}$.

Corroded samples were measured again by Raman spectroscopy, multiple spectra were collected on each sample for the sake of more reliable results. It was possible to measure the spectra below the layer of corrosion products, up to a depth of several micrometers. However, that was possible only at samples with thinner layer of corrosion products (Na16, Na20, K16, K20). Samples that were exposed to $\mathrm{HCl}$ for a longer time were covered by thick layer of corrosion products that prevented the collection of spectra from the depth.

The experiment was performed on TESCAN LYRA 3 scanning electron microscope (SEM) coupled with WiTec Raman spectrometer that is equipped with 600 lines $/ \mathrm{mm}$ grating and Carl Zeiss Optics objective (100x magnification). The semiconductor laser with a wavelength of $532 \mathrm{~nm}$ was used as an excitation source. The laser output has a maximal value of $75 \mathrm{~mW}$, but the power had to be often reduced due to the occurrence of possible photochemical phenomena and for the suppression of luminescence. The resolution/intensity variations of the Raman measurements are up to $2 \mathrm{~cm}^{-1} / 2 \%$, respectively. The advantage of using the coupled SEM/Raman device lies in the possibility of examining the surface of the sample by SEM under low accelerating voltage (the samples were not coated) and then switching to Raman for the collection of spectra. In order to minimize accidental errors multiple spectra were taken from each sample. Recorded spectra were subsequently cut, spectra were not smoothed, only cosmic peaks were removed.

\section{Results}




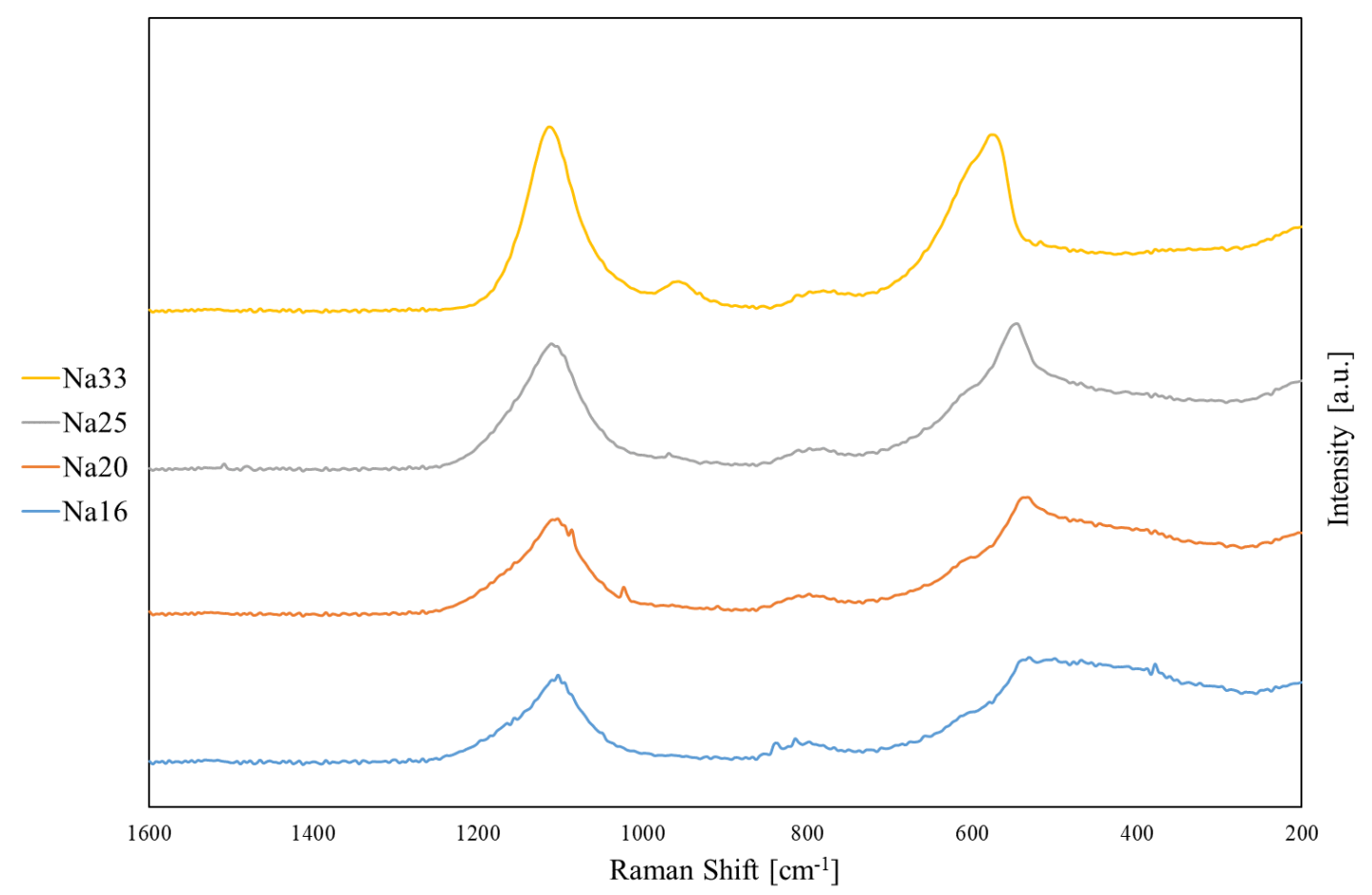

Fig. 1: Raman spectra of four binary sodium silicate glasses with increasing amount of sodium.

Fig. 1 presents the set of Raman spectra taken from binary sodium silicate glasses with different amount of sodium. The spectra are vertically shifted in order to avoid their overlapping for sake of better visibility. The dominant band located around 500 $\mathrm{cm}^{-1}$ corresponds to the oxygen breathing vibrations of the $\mathrm{Si}-\mathrm{O}-\mathrm{Si}$ linkage within large rings of $\mathrm{SiO}^{4}$ tetrahedra in the glass framework [28 - 30]. The relatively small peak at $602 \mathrm{~cm}^{-1}$ is also denoted as D2 peak and corresponds to the symmetric oxygen breathing vibrations of three-membered siloxane rings of $\mathrm{SiO}^{4}$ tetrahedra embedded as defects within the glass structure $[31,32]$. The band located at $800 \mathrm{~cm}^{-1}$ can be assigned to the $\mathrm{Si}-\mathrm{O}$ stretching vibration with dominant $\mathrm{Si}$ motion [33]. The 900-1200 $\mathrm{cm}^{-1}$ frequency region is assigned to the $\mathrm{Si}-\mathrm{O}$ symmetric bond stretching motions of the so-called $\mathrm{Q}^{n}$ species (i.e. $\mathrm{SiO}_{4}$ units with $n$ bridging oxygen atoms) [34].

The position and shape of the band at $500-600 \mathrm{~cm}^{-1}$ is changing with the increasing sodium content. The band of Q-motives placed at around $1100 \mathrm{~cm}^{-1}$ does not change rapidly, but a small band is visible at $940 \mathrm{~cm}^{-1}$ for the samples with higher alkali content. 


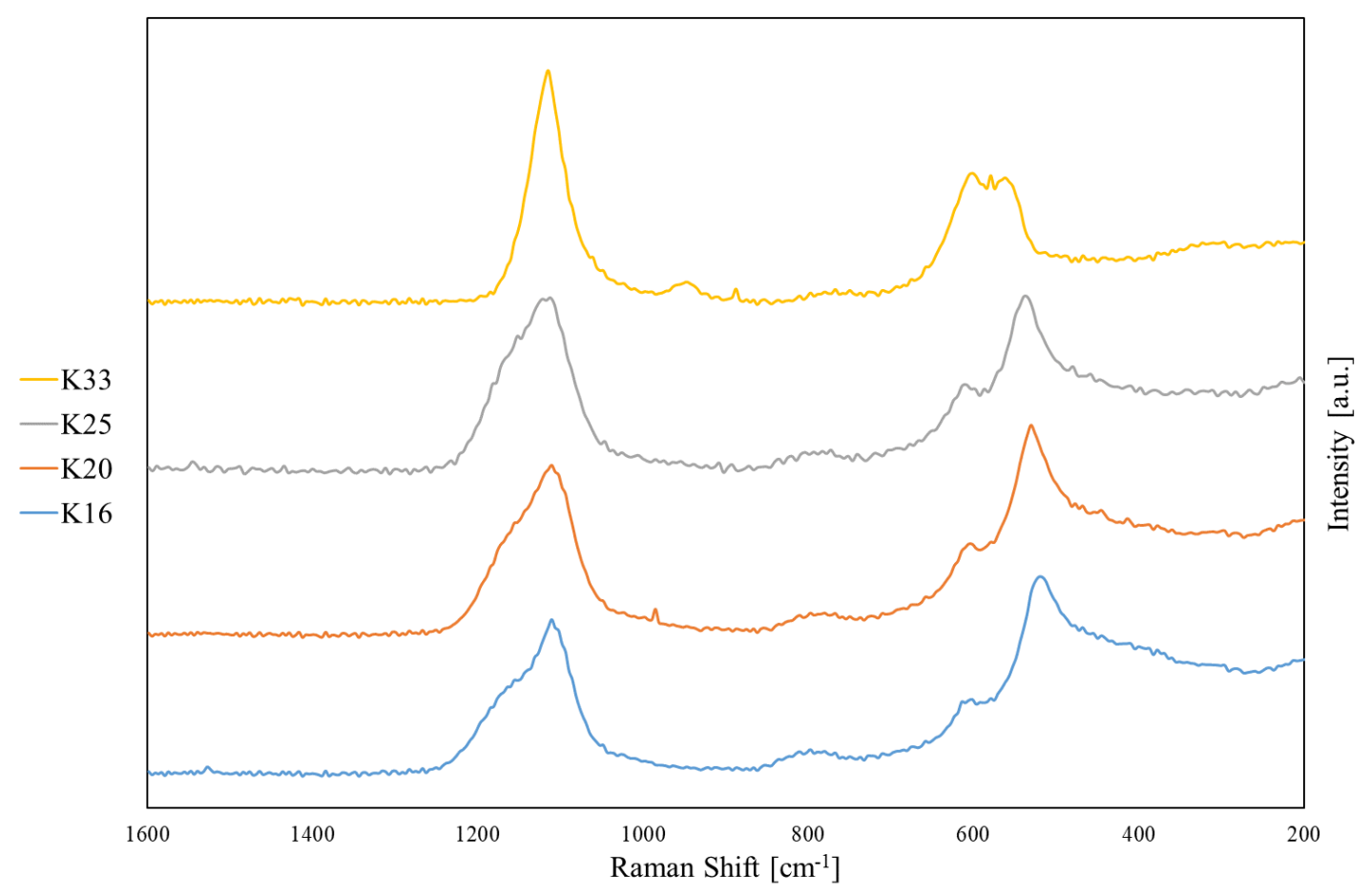

Fig. 2: Raman spectra of four binary potassium silicate glasses with increasing amount of sodium.

The similar evolution can be observed for binary potassium glasses on Fig. 2. The band at $500 \mathrm{~cm}^{-1}$ is shifting towards higher wavenumbers with the increasing potassium content. The intensity of D2 peak at $602 \mathrm{~cm}^{-1}$ is also increasing. The shape of Q-motives band is changing as a function of alkali content - the shoulder located at the high-frequency side of the band disappears.

Glass samples were corroded in $\mathrm{HCl}$, the times of exposure are summarized in Tab. 2 . Subsequently after the exposition and the removal from the corrosive environment, the samples were examined by SEM, where the growth of corrosion products was confirmed with increasing corrosion time. Figs. $3-4$ show the SEM images of corrosion on the surface of sodium glasses. 


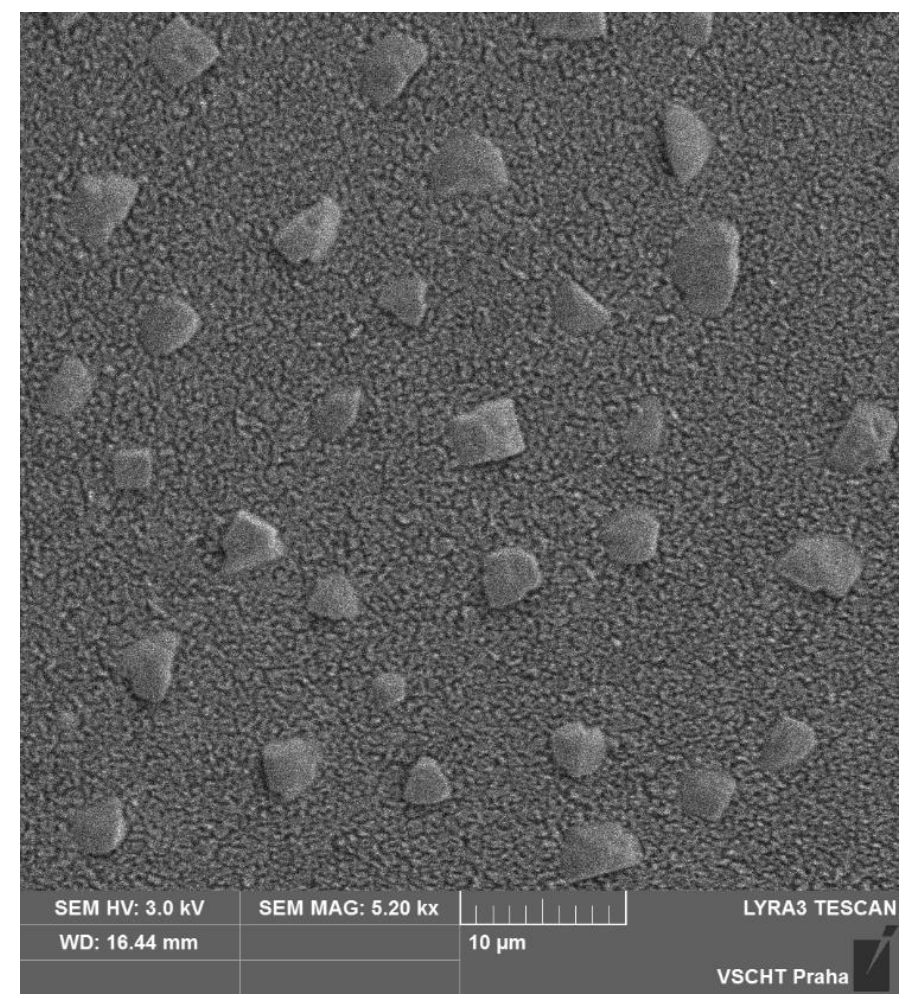

Fig. 3: SEM image of the surface of Na16 sample exposed to the corrosion for 160 minutes (magnification 5200x).

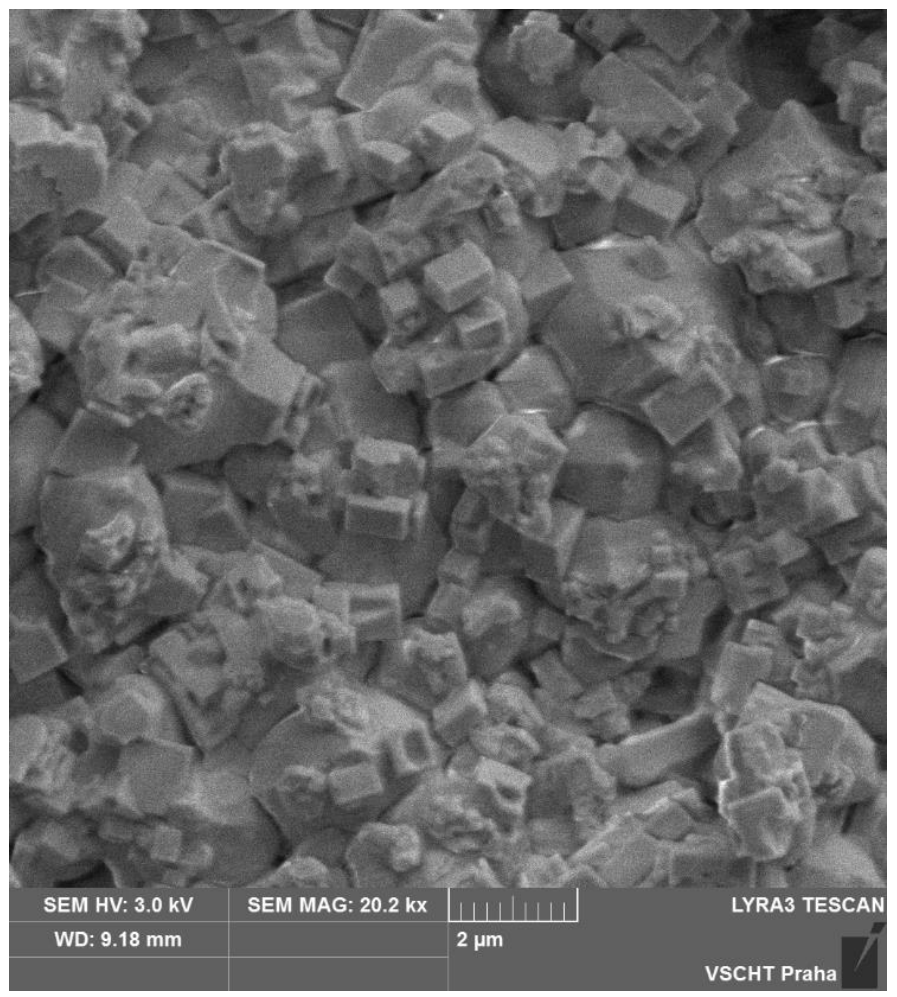

Fig. 4: SEM image of the surface of Na25 sample exposed to the corrosion for 2560 minutes (magnification 20200x). 
Presented images show the formation of cubic-shaped corrosion products that likely points to the growth of chloride crystals $(\mathrm{NaCl} / \mathrm{KCl})$. The layer of crystalline corrosion products was also examined by Raman spectroscopy, but the quality of the results was deteriorated by the fluorescence. However, the aim of this paper was to examine the changes of the glass structure on the surface, just below the layer of the corrosion products. It was possible to underfocus the laser and measure the spectra under the layer only for Na16, Na20, K16 and K20 samples. The other samples were exposed to corrosion for a longer time, which resulted in a thick layer of corrosion products on the surface (Fig. 4) that did not allow the laser beam to penetrate through.

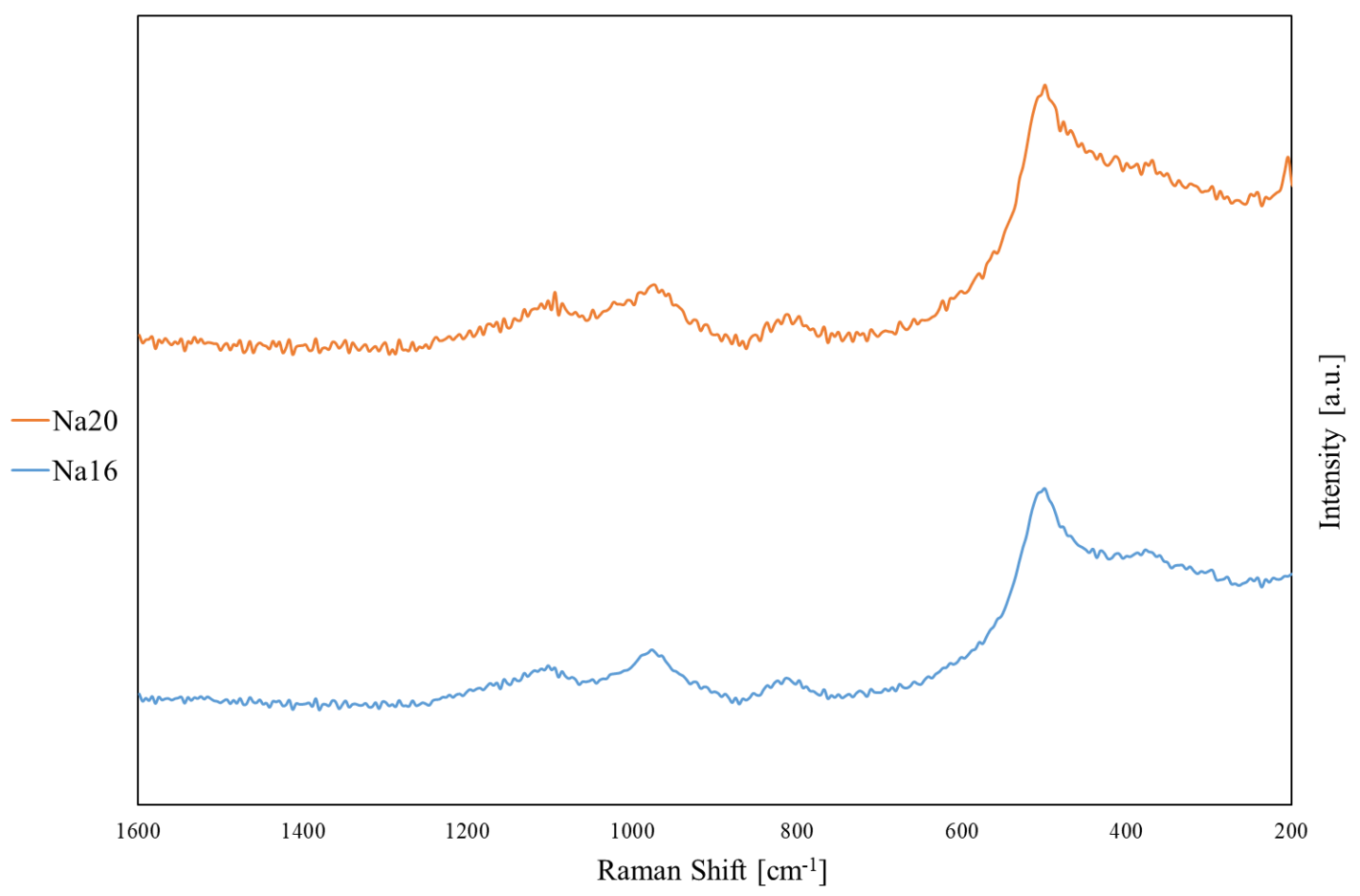

Fig. 5: Raman spectra of Nal6 and Na20 glasses after the exposition to HCl. Both spectra were taken from the surface (under the layer of corrosion products).

Fig. 5 shows the comparison between spectra of Na16 and Na20 samples taken from the surface. It is obvious that the intensity of Q-motives band decreased in comparison with the spectra of original pristine samples. In addition, the shape of the band changed - a new peak at $1000 \mathrm{~cm}^{-1}$ appeared. That points at the change of polymerization degree of the silicate structure at the surface after the exposure to $\mathrm{HCl}$. Then, D2 peak at $602 \mathrm{~cm}^{-1}$ disappeared. However, despite the different alkali content, both spectra are literally identical that may point at the saturation of the changes induced by corrosion on the surface. 


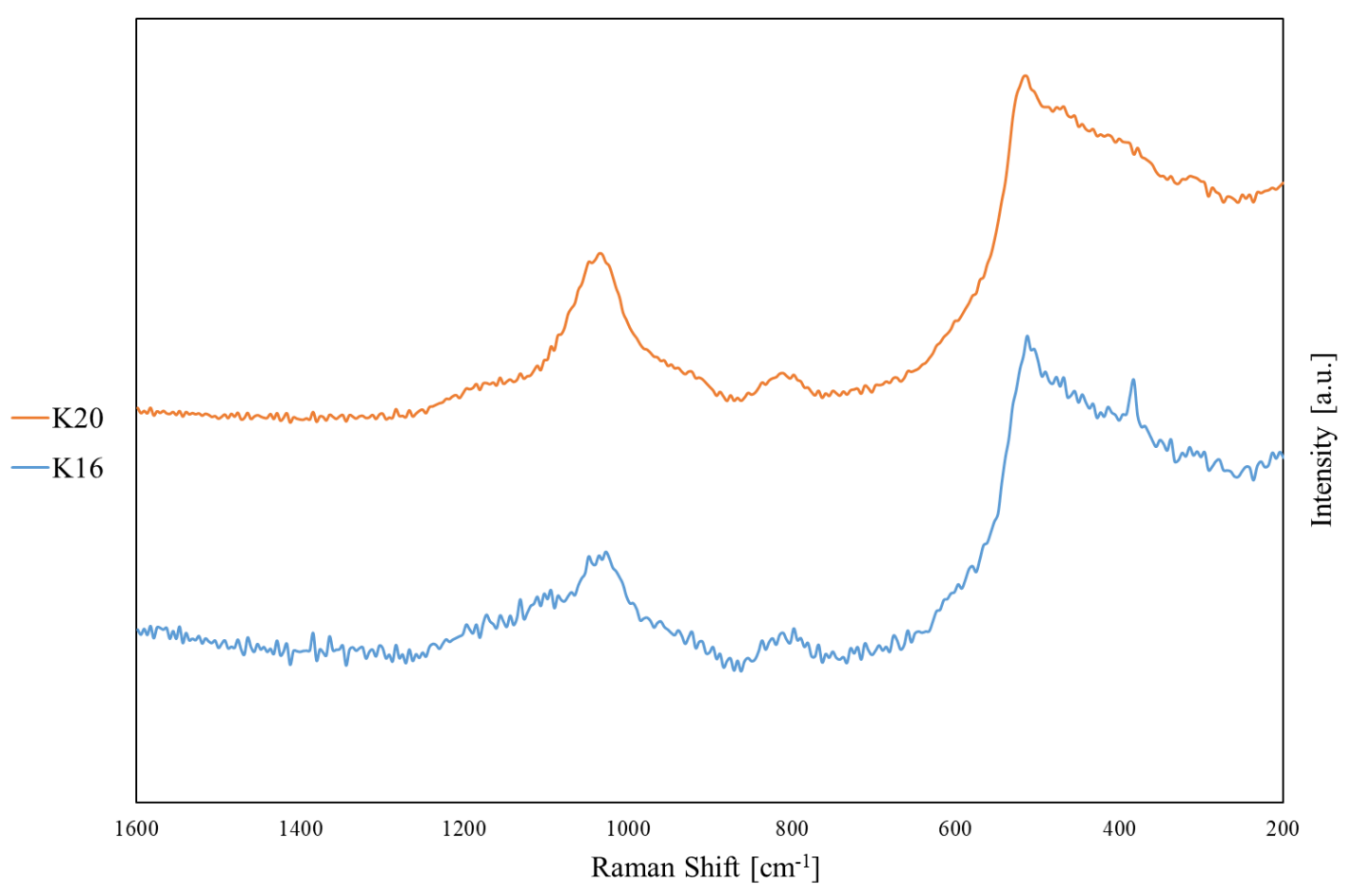

Fig. 6: Raman spectra of $\mathrm{K} 16$ and $\mathrm{K} 20$ glasses after the exposition to $\mathrm{HCl}$. Both spectra were taken from the surface (under the layer of corrosion products).

The spectra of K16 and K20 samples exhibit the similar evolution. The Q-motives band decreased, shifted towards lower frequencies and D2 peak disappeared after corrosion.

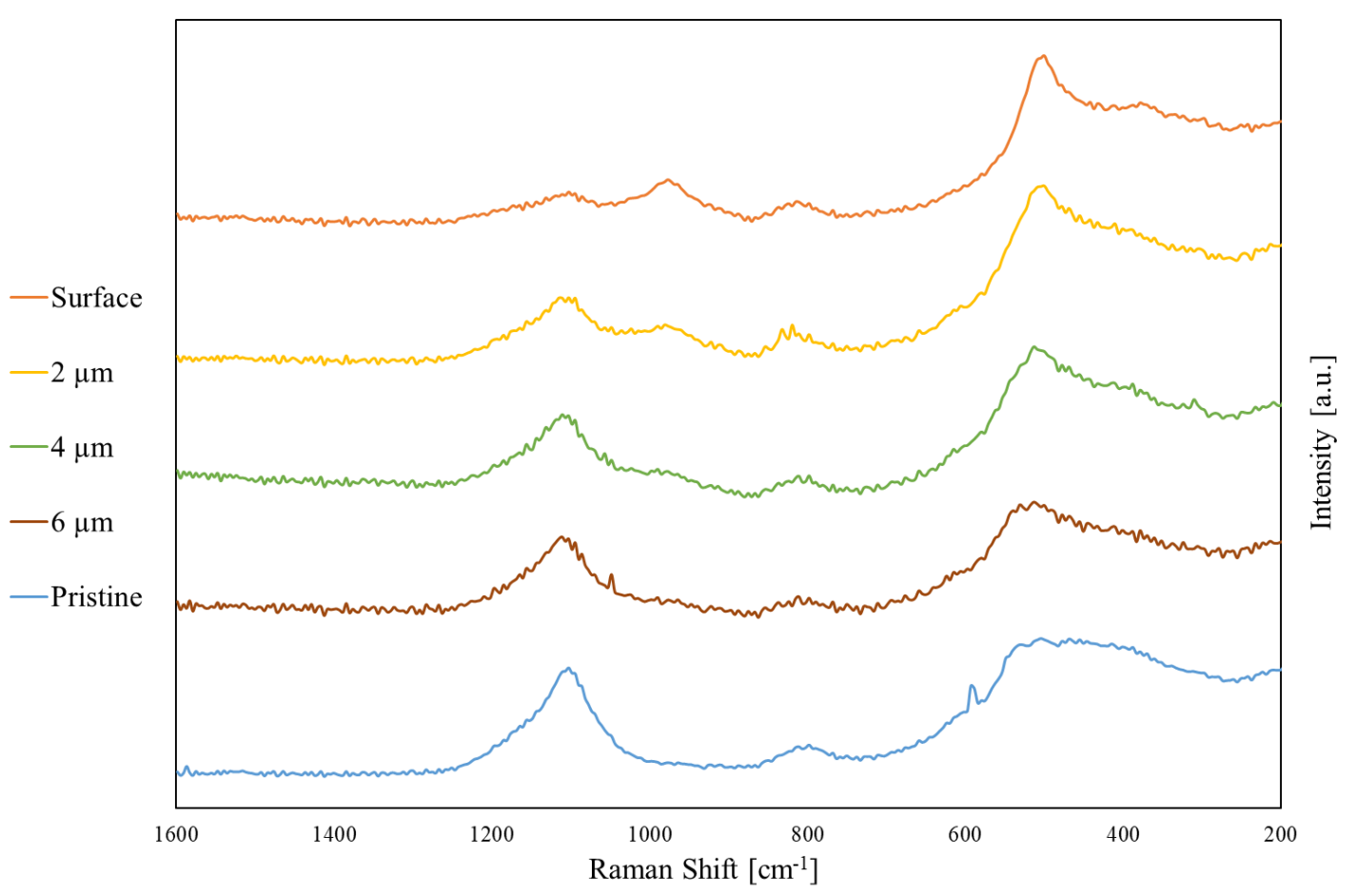


Fig. 7: Raman spectra of corroded Nal6 glass taken from different depth under the surface. The spectrum at the bottom is the spectrum of pristine Nal6 glass for comparison.

Fig. 7 presents the set of Raman spectra taken from various depths. The spectrum at the top was taken on the glass surface (directly under the corrosion layer) and subsequently the depth profiling continued with a step of $1 \mu \mathrm{m}$, until a noticeable decrease of intensity made impossible to collect any spectrum. The spectrum of original, non-corroded glass was added to the bottom for the comparison.

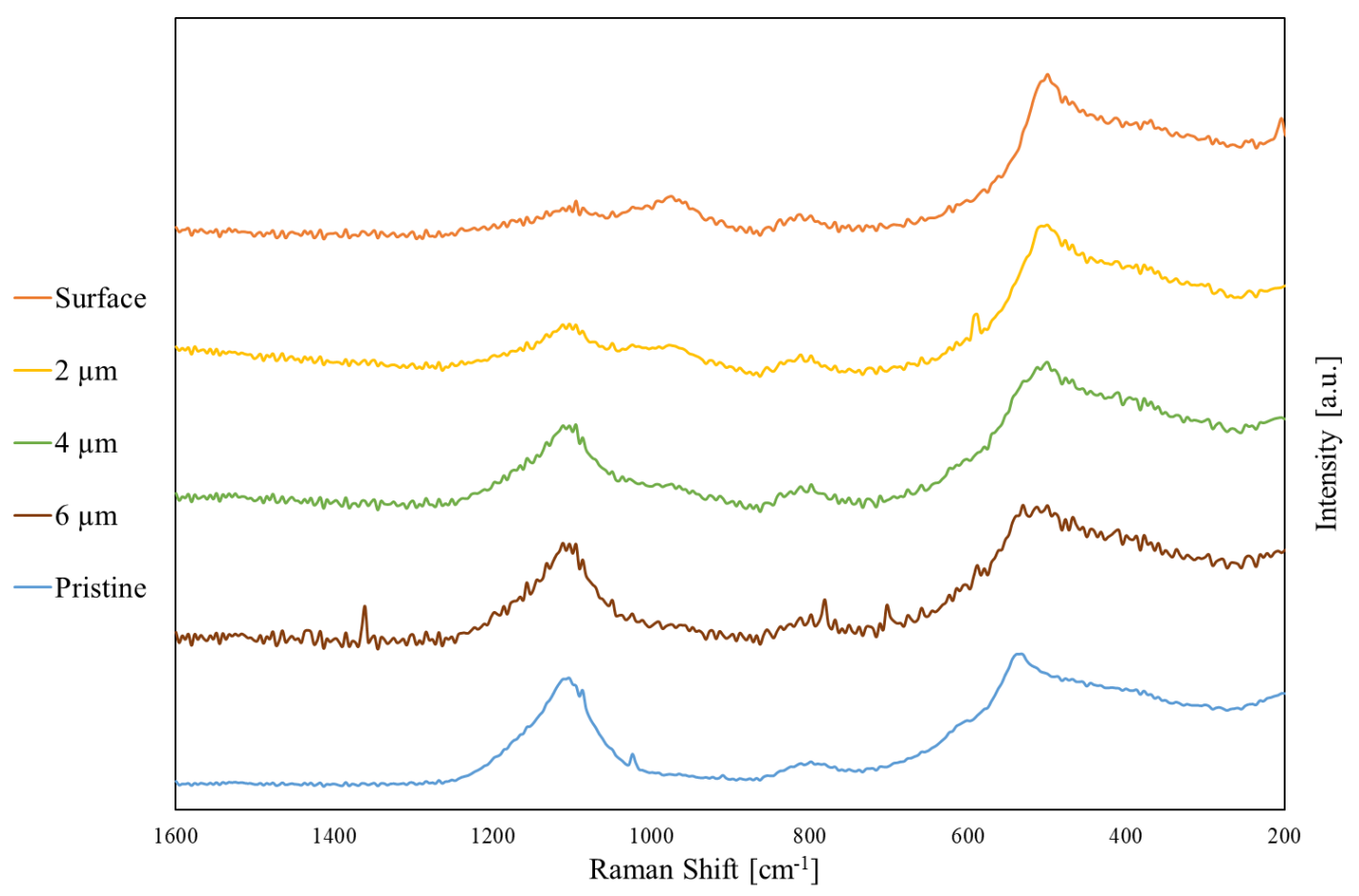

Fig. 8: Raman spectra of corroded Na20 glass taken from different depth under the surface. The spectrum at the bottom is the spectrum of pristine Na20 glass for comparison.

Raman depth profiles of $\mathrm{Na} 20$ glass show the similar evolution in comparison to Na16 glass. As we go from the surface to the depth, the Q-motives band changes from twin peak to a single band. The peak located at $1000 \mathrm{~cm}^{-1}$ disappears, while the peak at $1100 \mathrm{~cm}^{-1}$ increases its intensity. Then, the band at $500 \mathrm{~cm}^{-1}$ changed its shape with the increasing depth and its shift towards higher wavenumbers is evident. It is apparent that the spectra from the depth are similar to the spectrum of original pristine glasses which points at the depth of structural changes induced by corrosion. 


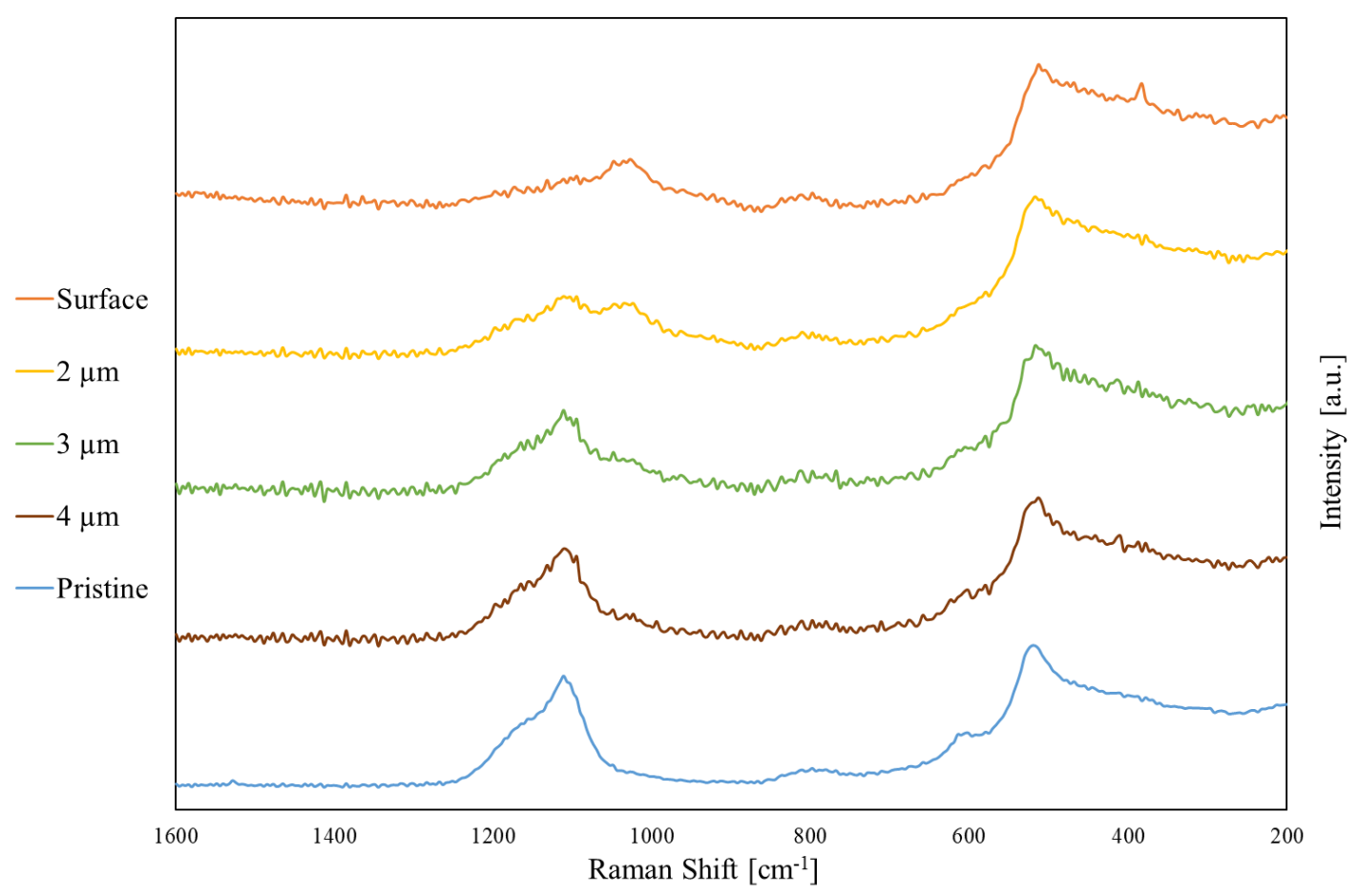

Fig. 9: Raman spectra of corroded K16 glass taken from different depth under the surface. The spectrum at the bottom is the spectrum of pristine K16 glass for comparison.

The evolution of Raman spectra with increasing depth for K16 samples is presented on Fig. 9. The shift of Q-motives band towards higher wavenumbers is obvious and D2 peak appeared on spectra from the depth. It is apparent that the spectra from the depth are comparable with the spectrum of original pristine glass, similar to the sodium glasses It suggests that the changes induced by corrosion are limited to few micrometers at the surface. 


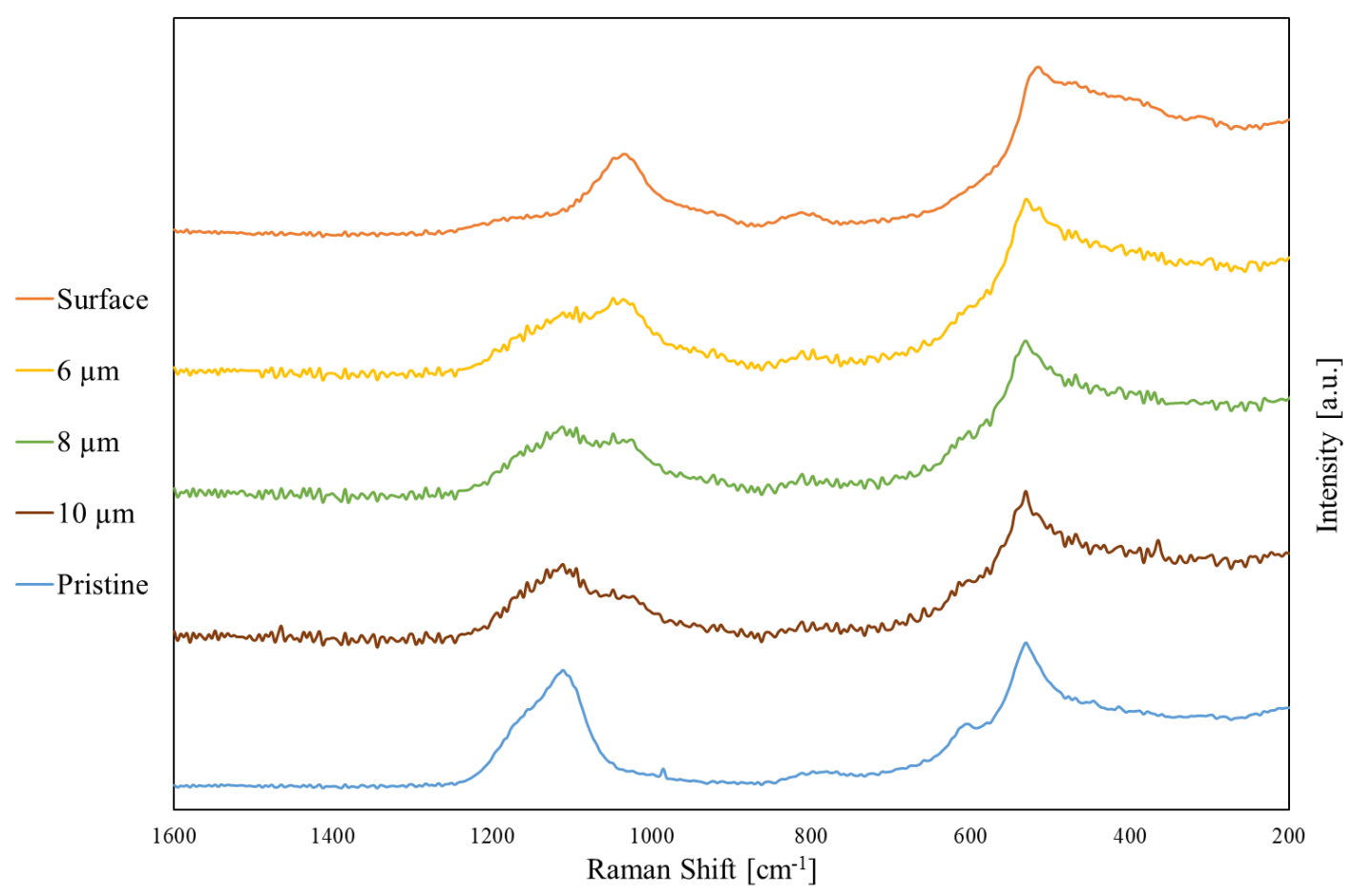

Fig. 10: Raman spectra of corroded K20 glass taken from different depth under the surface. The spectrum at the bottom is the spectrum of pristine K20 glass for comparison.

It was possible to collect the spectra of K20 glass up to a depth of $10 \mu \mathrm{m}$ (Fig. 10). The evolution of spectra with the increasing depth follows a similar trend to that of K16 glass. Raman spectra from the depth are becoming similar to that of the pristine glass before the corrosion, but the depth of the structural changes is much bigger, due to the longer time of exposure to the corrosion.

\section{Discussion}

The analysis of the binary sodium-silicate glass (Fig. 1) shows the following changes with increasing alkali content: there is an increase in the intensity of the peaks centered at $490 \mathrm{~cm}^{-1}$ and $602 \mathrm{~cm}^{-1}$, referred to as D1 and D2 peaks. The increase of these peaks points at the increased number of four- and three-membered rings in the glass

structure [35] with a higher alkali content. In addition, the shift of the whole band located at $600 \mathrm{~cm}^{-1}$ towards higher wavenumbers is visible, which corresponds to the change of $\mathrm{Si}-\mathrm{O}-\mathrm{Si}$ angle with increasing amount of sodium in the structure [20]. The change is also visible in the Q-motives band, where the shape of the peak at $1100 \mathrm{~cm}^{-1}$ does not change, but the spectrum of $\mathrm{Na} 33$ glass shows an increasing peak at approximately $940 \mathrm{~cm}^{-1}$, indicating the presence of $\mathrm{Q}^{0}$ motives. Similar effects were observed for binary potassium-silicate glass (Fig. 2). The intensity of D2 peak is increasing, the band at $500-600 \mathrm{~cm}^{-1}$ is shifted towards higher wavenumbers, a new band at $940 \mathrm{~cm}^{-1}$ is also visible on the spectrum of K33 glass, and the Q-motives band is shifting towards lower wavenumbers. Thus, both binary glasses likely exhibit the depolymerization of the silicate network with increasing alkali content. The spectra of glasses with the highest alkali content actually exhibit some similar features (presence of sharp peaks) to those of the respective crystalline phases. It is particularly evident 
from the sharpness of the Q-motives band and from the fact that spectra had to be taken multiple times to record a spectrum without any sharp peaks. That indicates the possible presence of a crystalline phase in the Na33 and K33 glasses, especially at the surface due to the corrosion caused by air humidity.

It was possible to measure the spectra in depth for Na16, Na20, K16 and K20 glasses, in order to detect structural changes in the glass surface layer due to corrosion. The results are qualitatively comparable for all these glasses. The shape and position of the Q-motives band is changing. This wide band is generally located between $900-1200$ $\mathrm{cm}^{-1}$ in the spectra of silicate glasses and corresponds to the symmetric bond stretching motions of the so-called $\mathrm{Q}^{n}$ species (i.e. $\mathrm{SiO}_{4}$ units with $n$ bridging oxygens) [34]. While the lowest wavenumbers (around $900 \mathrm{~cm}^{-1}$ ) correspond to the vibrations of $\mathrm{Q}^{0}$ units, the highest wavenumbers belong to the vibrations of $\mathrm{Q}^{4}$ units. The exact positions of particular Q-units may vary depending on the system composition. Generally, this band may be referred to as an indicator of the degree of polymerization of the glass network. Spectra from the surface of corroded glass indicate the depolymerization of the surface layer due to corrosion. Fig. 10 shows that $\mathrm{Q}^{2}$ motives are present on the surface of K20 glass (the band is centered at approximately $1040 \mathrm{~cm}^{-1}$ ). The band intensity starts to decrease with the increasing analysis depth and at the same time it is possible to observe the increase of the band at $1100 \mathrm{~cm}^{-1}$, corresponding to $\mathrm{Q}^{3}$ motives. It is apparent that the spectra taken from the deeper locations under the surface are becoming similar to the spectra of the original glass, so as we penetrate deeper, we are approaching the structure of the original, noncorroded glass. The experiment with K16 glass shows almost identical results, the difference is only in the value of the depth at which the "original" structure is achieved. K20 glass was exposed to corrosion for longer time so the depth of the changed structure is bigger, hence, the spectrum taken from the depth of $10 \mu \mathrm{m}$ is still not identical with that of pristine glass. Sodium glasses exhibit the similar trend, the presence of the band corresponding to $\mathrm{Q}^{1}$ motives (approximately at $980 \mathrm{~cm}^{-1}$ ) is visible on the surface of the corroded glass (that band is present also in the spectra of potassium glasses, but relatively weak). However, as depth penetrates, lower Q-motives gradually disappear. The D2 peak is not found on the spectrum of corroded surface layer, but its intensity increases with the depth (confirmed for all glasses), which corresponds to the decomposition of three-membered rings due to corrosion. All observed glasses exhibit the shift of the band at $500 \mathrm{~cm}^{-1}$ towards higher wavenumbers with the increasing depth. This band corresponds to the vibrations of the $\mathrm{Si}$ - O - Si linkage and it was suggested in previous studies that there is an inverse correlation between the frequency of this band and the value of the $\mathrm{Si}-\mathrm{O}$ - Si angle $[36,37]$. Hence, the shift towards higher wavenumbers indicates the decrease of mentioned angle. Results of studies suggest that a shift of this band by $5.5 \mathrm{~cm}^{-1}$ indicates an angle change of $1^{\circ}[28]$.

Both sodium and potassium glasses exhibit the similar trend when exposed to corrosion, although the ratio between particular Q-motives is different (Figs. 5 - 6). Although $\mathrm{Na} 16$ and $\mathrm{Na} 20$ glasses differ in alkali content and were exposed to $\mathrm{HCl}$ for a different time, the spectra from the surface are almost identical (Fig. 5). This may suggest that the processes that took place in the surface layer have become saturated, and even longer exposition to corrosion environment would cause no structural changes. On the other hand the difference between K16 and K20 spectra (Fig. 6) is still visible, so the structural change of K16 surface would likely to continue with further exposition to corrosion. 


\section{Conclusion}

Binary sodium and potassium glasses with different alkali contents were measured. Raman spectroscopy describes the structure of these model systems. The glasses were exposed to corrosion by $\mathrm{HCl}$. Subsequently, structural changes induced by corrosion were investigated by means of Raman spectroscopy. Depth profiles were measured to document the extent of corrosion towards the bulk. It was that corrosion causes depolymerization of the glass in the surface layer, which can be explained by the departure of alkali ions caused by the formation of corrosion products on the glass surface. The decomposition of the three-membered cycles due to corrosion was documented, which is obvious from the decrease of the D2 peak intensity. Raman spectra also suggest that $\mathrm{Si}-\mathrm{O}-\mathrm{Si}$ angle is being changed by the corrosion.

Acknowledgment:

This work was supported by The Slovak Grant Agency for Science under grant No VEGA 1/0064/18, and by the Slovak Research and Development Agency project APVV SK-PL-180062, and the project Centre for Functional and Surface Functionalized Glass (CEGLASS), ITMS code is 313011R453, operational program Research and innovation, co-funded from European Regional Development Fund.

\section{References}

[1] A. Tournié, P. Ricciardi, Ph. Colomban, Glass corrosion mechanisms: A multiscale analysis, Solid State Ionics 179 (2008) 2142.

[2] R.B. Ellestad, K.K. Leute, brevet US 2516 109, 25/07/1950 (1950).

[3] Y.I. Ostroushko, K.I. Filipova, L.A.Ignateva, Reaction of $\beta$-spodumene with sulfuric acid, Russ. J. Inorg. Chem 7 (1962) 126.

[4] R.H. Doremus, Interdiffusion of hydrogen and alkali ions in a glass surface, J. Non-Cryst. Solids 19 (1975) 137.

[5] P. Lenfant, D. Plas, M. Ruffo, J.P. Boilot, Ph. Colombar, Ceramiques d'alumine $\beta$ et de ferrite $\beta$ pour sonde a protons, Mater. Res. Bull. 15 (1980) 1817.

[6] Y.F.Y. Yao, J.T. Kummer, Ion exchange properties of and rates of ionic diffusion in beta-alumina, J. Inorg. Nucl. Chem. 29 (1967) 2453.

[7] H. Saalfield, H. Matthies, S.K. Datta, Ein Neues Aluminiumoxid- Hydrat mit P-Alumina Struktur, Ber. Dtsch. Keram. Ges. 45 (1968) 212.

[8] T. Geisler, A. Janssen, D. Scheiter, T. Stephan, J. Berndt, A. Putnis, Aqueous corrosion of borosilicate glass under acidic conditions: a new corrosion mechanism, J. Non-Cryst. Solids 356 (2010) 1458. 
[9] T. Geisler, T. Nagel, M.R. Kilburn, A. Janssen, J.P. Icenhower, R. Fonseca, M. Grange, A.A. Nemchin, The mechanism of borosilicate glass corrosion revisited, Geochim. Cosmoch. Acta 158 (2015) 112.

[10] P. Frugier, et al., SON68 Nuclear Glass Dissolution Kinetics: Current State of Knowledge and Basis of the New GRAAL Model, J. Nucl. Mater., 380 (2008) 8.

[11] C. Jégou, S. Gin, F. Larché, Alteration kinetics of a simplified nuclear glass in an aqueous medium: effects of solution chemistry and of protective gel properties on diminishing the alteration rate, J. Nucl. Mater., 280 (2000) 216.

[12] D. Rebiscoul, et al., Morphological evolution of alteration layers formed during nuclear glass alteration: New evidence of a gel as a diffusive barrier, J. Nucl. Mater., 326 (2004) 9.

[13] A. Černá, B. Hruška, D. Tokarčíková, M. Chromčíková, M. Liška, Optical microscopy, Raman spectroscopy, and AFM study of heavy weathered surface of barium crystal glass, Chemical Papers 72 (2018) 2153.

[14] R. Prochazka, Natural Corrosion of the Uranium-Colored Historical Glasses, J. Non-Cryst. Solids, 352 (2007) 2052.

[15] A. Rodrigues, S. Fearn, M. Vilarigues, Historic K-rich silicate glass surface alteration: Behaviour of high-silica content matrices, Corrosion Science Vol. 145 (2018) 249.

[16] E. Greiner-Wrona, P. Świt, The Influence of Selected Organic Compounds on the Corrosion of Historical Glass Based on Their State of Preservation, Acta Physica Polonica, Series A 130(6) (2016) 1406.

[17] A. Ledieu, F. Devreaux, P. Barboux, Monte Carlo simulations of borosilicate glass corrosion: predictions for morphology and kinetics, J. Non-Cryst Solids 345-346 (2004) 715.

[18] N. Ollier, O. Gedeon, Micro-Raman studies on $50 \mathrm{keV}$ electron irradiated silicate glass, J. Non-Cryst. Solids 352 (2006) 5337.

[19] B. Boizot, G. Petite, D. Ghaleb, B. Reynard, G. Calas, Raman study of $\beta$ irradiated glasses, J. Non-Cryst. Solids 243 (1999) 268.

[20] B. Boizot, S. Agnello, B. Reynard, R. Boscaino, G. Petite, Raman spectroscopy study of $\beta$-irradiated silica glass, J. Non-Cryst. Solids 325 (2003) 22.

[21] D.W. Matson, S.K. Sharma, J.A. Philpotts, The structure of high-silica alkalisilicate glasses. A Raman spectroscopic investigation, J. Non-Cryst. Solids 58 (1983) 323.

[22] M. Chromčíková, M. Liška, J. Holubová, Z. Černošek, Structure of As2S3Sb4S4 glasses by combined Raman spectroscopy and thermodynamic modeling approach, J. Non-Cryst. Solids 401 (2014) 115.

[23] M. Chromčíková, M. Liška, T. Gavenda, J. Macháček, Structure of Na2O$\mathrm{MgO}-\mathrm{CaO}-\mathrm{SiO} 2$ glasses by combined Raman spectroscopy and thermodynamic modeling approach, J. Therm. Anal. Calorimetry 118 (2014) 835 . 
[24] Černošek Z., Holubová J. The structure and certain properties of $\mathrm{CaO}-\mathrm{In}_{2} \mathrm{O}_{3}$ $\mathrm{P}_{2} \mathrm{O}_{5}$ glasses. J. Non-Cryst. Solids 490 (2018) 44.

[25] A.A. Osipov, L.M. Osipova, B. Hruska, A.A. Osipov, M. Liska, FTIR and Raman spectroscopy studies of $\mathrm{ZnO}$-doped $\mathrm{BaO} \cdot 2 \mathrm{~B}_{2} \mathrm{O}_{3}$ glass matrix, Vib. Spectrosc. 103 (2019) 102921.

[26] B. Hruska, A.A. Osipov, L.M. Osipova, M. Chromčíková, J. Macháček, M. Liška, Thermodynamic model and Raman spectra of $\mathrm{BaO}-\mathrm{B}_{2} \mathrm{O}_{3}$ glasses, Vib. Spectrosc. 105 (2019) 102970.

[27] M. Chromčíková, A.A. Osipov, L.M. Osipova, B. Hruska, M. Liška, R. Svoboda, Thermodynamic model and high temperature Raman spectra of $\mathrm{Na}_{2} \mathrm{O}-\mathrm{B}_{2} \mathrm{O}_{3}$ glassforming melts, JALLCOM. 798 (2019) 700.

[28] M. Okuno, B. Reynard, Y. Shimada, Y. Syono, C. Willaime, Phys. Chem. Miner. 26 (1999) 304.

[29] P. McMillan, B.T. Poe, P.H. Gillet, B. Reynard, A Raman spectroscopic study of shock-wave densification of vitreous silica, Geochim. Cosmochim. Acta 58 (1994) 3653.

[30] F.L. Galeener, A.F. Geissberger, Vibrational dynamics in ${ }^{30}$ Si-substituted vitreous $\mathrm{SiO}_{2}$, Phys. Rev. B 27 (1983) 6199.

[31] D. Sykes, J.D. Kubicki, Four-membered rings in silica and aluminosilicate glasses, Am. Miner. 81 (1996) 265.

[32] A. Pasquarello, R. Car, Identification of Raman defect lines as signatures of ring structures in vitreous silica, Phys. Rev. Lett. 80 (23) (1998) 5145.

[33] B.O. Mysen, Structure and Properties of Silicate Melts, Elsevier, Amsterdam, (1988) 354.

[34] P.F. McMillan, G.H. Wolf, Structure, Dynamics, and Properties of Silicate Melts Reviews in Mineralogy n.32, Mineralogical Society of America, Washington DC, 1995.

[35] T. Gavenda, O. Gedeon, K. Jurek, Structural and volume changes and their correlation in electron irradiated alkali silicate glasses, Nucl. Instrum. Methods Phys. Res. B 397 (2017) 15.

[36] F.L. Galeener, P.N. Sen, Theory for the first-order vibrational spectra of disordered solids, Phys. Rev. B 17 (1978) 1928.

[37] P. McMillan, Structural studies of silicate glasses and melts - applications and limitations of Raman spectroscopy, Am. Miner. 69 (1984) 622. 